\title{
Hyaluronic acid dermal fillers: can adjunctive lidocaine improve patient satisfaction without decreasing efficacy or duration?
}

This article was published in the following Dove Press journal:

Patient Preference and Adherence

I4 March 201 I

Number of times this article has been viewed

\author{
Lynnelle Smith' \\ Kimberly Cockerham ${ }^{2}$ \\ 'Ophthalmology Department, \\ Loma Linda University, Loma Linda, \\ CA, USA; ${ }^{2}$ Ophthalmology \\ Department, Stanford University, \\ Palo Alto, CA, USA
}

\begin{abstract}
Hyaluronic acid (HA) dermal fillers are the most widely used injectables to augment facial volume without surgery. HA dermal fillers are popular because of their ease of administration, predictable effectiveness, good safety profile, and quick patient recovery. The most common patient complaint is pain. Our goal is to review the current literature on HA fillers and compare outcomes with and without lidocaine. We found adjunctive lidocaine significantly decreases pain during injection and postinjection with corresponding increased patient satisfaction. The efficacy and safety profile appears unchanged. Rare complications with HA fillers and those associated with constituents of the product, contaminants, and lidocaine are reviewed. The corrective effects of HA fillers are temporary; repeat treatment is required to maintain results. Minimizing pain is crucial to optimize patient satisfaction.
\end{abstract}

Keywords: hyaluronic acid, lidocaine, drug toxicity, hypersensitivity, collagen, herpes simplex

\section{Introduction}

The major determinants of facial aging are a combination of nature and nurture, including sun exposure, smoking, muscle activity, and genetics. ${ }^{1}$ Decreased collagen production, loss of elastin, muscle hyperactivity, atrophy of bone, and soft tissue structure lead to aging changes in the face. These are heralded by skin laxity and volumetric loss and redistribution. ${ }^{2-4}$ For deep facial wrinkles, dermal fillers have the unique ability over botulinum toxin injection and surgical tightening procedures to augment tissue volume. The potential to restore youthful contour, shaping, and fullness has made dermal fillers one of the fastest growing minimally invasive aesthetic procedures within the United States.

The global revenue of the cosmetic surgery industry was USD 31.7 billion in 2008 and projected to reach USD 40.1 billion by 2013. In 2008, the largest demographic group to receive services was aged between 40 and 54 years. ${ }^{5}$ An ASOPRS survey conducted this same year indicated hyaluronic acid (HA) dermal fillers alone accounted for more than 1 million of these aesthetic procedures. ${ }^{2}$

In our fast-paced, aging society, ideal aesthetic procedures are safe, quick, effective, and painless. HA dermal fillers meet this demand in many ways and have a lower risk of allergic reaction compared to previously used collagen fillers. ${ }^{6,7}$ Their greatest future obstacles are pain management and duration of action. ${ }^{2-4,6-8}$ This article reviews previous studies that compare pain management with and without adjunct lidocaine and the adverse effects of HA dermal fillers and those unique to
Correspondence: Kimberly Cockerham 762 Altos Oaks Drive, Suite 2,

Los Altos, CA 94024, USA

$\mathrm{Tel}+\mathrm{I} 6508049270$

Fax + I $650559915 \mid$

Email kpcorb@aol.com 
fillers with adjunct lidocaine. We expect that the addition of lidocaine will reduce experienced pain during injection and postinjection.

\section{Materials and methods}

This literature review was completed using the PubMed search engine. The search terms used were combinations of the following: hyaluronic acid, dermal fillers, liquid face-lift, lidocaine, collagen, drug toxicity, hypersensitivity, allergy, allergic reaction, nodules, abscess, and herpes simplex. All relevant articles pertaining to the focus of this study were selected and incorporated into this article. Additional articles were also identified through the review of the references within this initial set. The availability of dermal fillers within the United States was confirmed via article review and verbal conversations directly between the authors of this article and the companies that produce each dermal filler.

\section{Background}

Collagen dermal fillers were introduced to the United States market in the 1980s followed by HA fillers in the 1990s. ${ }^{4,9}$ HA is a transparent, highly refractile molecule that derives its name from the Greek term 'hyalos' meaning glass. Its was originally isolated from bovine vitreous humor by the scientists Karl Meyer and John Palmer at Columbia University in New York City, NY. The commercial uses of HA are largely developed by Endre Balazs, who initially patented its use for egg-white substitute in baked goods and is responsible for applying HA to multiple medical uses over the past 50 years. ${ }^{9}$

\section{The science \\ $\mathrm{HA}$}

HA occurs naturally within the human body as an extracellular protein polysaccharide without species or tissue chemical specificity. It is biocompatible and can retain up to 1000 times its weight in water. HA undergoes isovolumetric degradation within the body; as it is reabsorbed, it takes on more water, retaining a similar amount of volume for a prolonged period of time. In its naturally occurring form, it is quickly eliminated from the body via the lymphatic and hepatic metabolism, having a half-life of $<2$ days in vivo. Commercially available HA is manufactured with crosslinking agents to extend its half-life including divinyl sulfone and butanediol diglycidyl ether. ${ }^{4,9}$ Botulinum toxin injection, administered with or prior to dermal filler, appears to also significantly improve the aesthetic result of HA filler treatment of the nasolabial fold (NLF). Two studies, by Custis et al and Carruthers and Carruthers, found that concurrent botulinium toxin and HA dermal filler treatment appeared to prolong the duration of correction by 6.5 and 14 weeks, respectively, compared to the treatment of HA dermal filler alone. ${ }^{6,10,11}$

\section{HA products currently Food and Drug Administration approved}

In the past, several of the collagen dermal fillers were manufactured with $0.3 \%$ lidocaine including Zyderm, Zyplast, and the synthetic filler, Artefill (polymethylmethacrylate microspheres suspended in bovine collagen). Several of the studies reviewed later within this article were generated by the need for clinical trials of lidocaine incorporated into HA dermal fillers to gain Food and Drug Administration (FDA) approval. The seven HA dermal fillers mentioned below were confirmed to be FDA approved and currently in production within the United States.

\section{HA dermal fillers without lidocaine}

Perlane is available through Medicis Corporation (Scottsdale, AZ). It is a bacterially derived HA from a Streptococcus species. It is formulated in a concentration of $20 \mathrm{mg} / \mathrm{mL}$ in a physiological buffer. Perlane is made of 'sized' HA particles, meaning it undergoes a process where cross-linked HA is filtered through a screen that breaks it into smaller pieces. Large-sized pieces are made into Perlane and medium-sized into Restylane ${ }^{\circledR}$ (Medicis Corporation). These larger particles make Perlane more appropriate for deeper injection sites than Restylane. Results last $\sim 6$ months. It was approved by FDA in 2007.

Restylane also includes a bacterially derived HA from a Streptococcus species. It is formulated in a concentration of $20 \mathrm{mg} / \mathrm{mL}$ in a physiological buffer. This filler does not contain an anesthetic, a preservative, or animal proteins and is made of 'sized' HA particles as described above. Results last approximately 6 months. It was approved by the FDA in 2003.

Juvéderm $^{\circledR}$ Ultra is available through Allergan Pharmaceuticals (Irvine, CA). It is a bacterial-derived, cross-linked HA from Streptococcus. It is formulated in a concentration of $24 \mathrm{mg} / \mathrm{mL}$ in a physiological buffer. This filler is not 'sized'. This is the only HA filler FDA had approved for correction of moderate to severe wrinkles to up to 1-year duration. Effects are estimated to last between 9 months and 1 year. It was FDA approved in 2007.

Two fillers frequently mentioned in the literature are no longer produced in the United States: Captique ${ }^{\circledR}$ and 
Hylaform ${ }^{\circledR}$. Captique contained $5.5 \mathrm{mg} / \mathrm{mL}$ of HA and consists of $98 \%$ highly cross-linked HA gel. Effects were estimated to last approximately 3-6 months. Hylaform was a HA filler produced from a modified avian source (rooster combs). Both were approved by the FDA in 2004 under InMed/Genzyme Corporation. These products were acquired by Allergan Pharmaceuticals in 2006 and production within the United States ceased in $2008 .^{6,7,12-15}$

\section{HA dermal fillers with lidocaine}

Prevelle ${ }^{\circledR}$ SILK is available through Mentor Corporation (Santa Barbara, CA). It is a bacterial-derived HA called hylan B gel which is 'sized'; previously, this compound was used in the production of Hylaform. This dermal filler has preincorporated $0.3 \%$ lidocaine. This was approved by the FDA in 2008

Juvéderm Ultra Plus XC (aka Juvéderm Ultra Plus) is available through Allergan Pharmaceuticals. It contains preincorporated $0.3 \%$ lidocaine and is estimated to last at least 12 months. In one study, it lasted over 12 months in a large percentage of patients than Juvederm Ultra. FDA approved it in 2010 .

Restylane-L and Perlane-L are manufactured by Medicis Corporation. They represent two different formulations of HA dermal fillers with preincorporated $0.3 \%$ lidocaine. Both were approved by FDA in 2010.

Hydrelle $^{\circledR}$ is available through Anika Therapeutics (Bedford, MA). It is HA filler that contains $0.3 \%$ preincorporated lidocaine. It is a bacterial-derived HA, formulated in a concentration of $28 \mathrm{mg} / \mathrm{mL}$ in a physiological buffer. It has been estimated to last for $\sim 6$ months. This dermal filler previously was marketed under the name Elevess and was approved by FDA in 2006. Its name was officially changed to Hydrelle through the FDA in 2009. Currently, Hydrelle is marketed within the United States. ${ }^{6,7,12,13,15}$

\section{Can dermal fillers be pain free?}

During administration of dermal fillers, pain remains the most consistent patient complaint. Topical, local, and nerve block lidocaine anesthesia and cooling systems have been employed with limited success. ${ }^{2,3,7}$ Topical anesthesia is often insufficient at completely eliminating pain and requires an extended period of time of onset. Nerve blocks are effective, but their prolonged duration of action and transient cosmetic side effects are often unsatisfactory to patients. Local anesthesia adequately controls pain but can distort the area of treatment, making it more difficult to determine the end point of treatment. ${ }^{2,4,7}$ HA dermal filler with adjunct lidocaine offers the potential for quick, effective treatment, decreasing procedural time (one-step anesthesia and treatment), and hastening recovery time for patients with minimal additional risk. Preincorporated lidocaine in collagen fillers is shown to cause less bruising and swelling after injection, which could translate to HA fillers. ${ }^{12}$ Lidocaine is also shown to function as an antihistamine in lower concentrations, inhibiting its release from mast cells. ${ }^{16}$ Decreasing these common side effects could increase patient and physician satisfaction, making HA fillers very much closer to a true 'lunchtime' procedure. Many collagen fillers already are manufactured with preincorporated anesthetic, ${ }^{8}$ and below we review the literature on HA fillers with lidocaine.

Incorporating lidocaine into HA fillers was publicly introduced within the United States in 2007. At the 34th Annual Scientific Meeting of the American Society of Dermatologic Surgery in Chicago, a new technique was introduced involving the use of a two-way connector to supplement the calcium hydroxylapatite dermal filler (Radiesse ${ }^{\circledR}$ ) with local lidocaine. Dr Mariano Busso described the use of female-to-female adaptors to add local lidocaine anesthesia to HA dermal fillers. Since then several surgeons have applied this method of adding adjunct lidocaine to HA dermal fillers. ${ }^{2}$

\section{Studies comparing outcomes of HA fillers with and without lidocaine}

Several studies that examined and compared HA fillers with and without lidocaine revealed significantly less pain and, in some, less erythema, swelling, and bruising with adjunct lidocaine (Table 1). All of the studies highlighted in this article focus on the primary outcome of pain during injection and postinjection. Almost all of the studies reviewed use a filler with $0.3 \%$ lidocaine (excluding Beasley et al and Lupo et al). ${ }^{1-4,8,17,18}$

Beasley et al conducted a retrospective chart review accounting for 439 patients receiving a total of 498 injections of either Restylane or Perlane. The filler included $\sim 0.1 \%$ lidocaine with 1:10,000 epinephrine added within the clinical setting by the authors using the technique described above by Dr Mariano Busso. All injections were administered with topical anesthetic cream. In review of patient charts for pain scores postinjection (1-10 rating scale), there were less with HA injections with lidocaine. No numeric values were tabulated. ${ }^{2}$

Monheit et al conducted a prospective, randomized, single-blind controlled trial comparing Prevelle SILK (preincorporated $0.3 \%$ lidocaine) versus Captique (same molecular filler without lidocaine). A split-face NLF injection 
Table I Studies of HA fillers with and without lidocaine

\begin{tabular}{|c|c|c|c|c|c|c|}
\hline Reference & Study type & $\begin{array}{l}\text { Number } \\
\text { of patients }\end{array}$ & $\begin{array}{l}\text { Lidocaine } \\
\text { concentration }\end{array}$ & Evaluation & Results & $\begin{array}{l}\text { Complications } \\
\text { and rate }\end{array}$ \\
\hline $\begin{array}{l}\text { Beasley } \\
\text { et } \mathrm{al}^{2}\end{array}$ & $\begin{array}{l}\text { Retrospective chart } \\
\text { review }\end{array}$ & $\begin{array}{l}439 \text { Patients, } \\
498 \text { injections }\end{array}$ & $\begin{array}{l}\text { Luer-lock method: } \\
0.1 \% \text { lidocaine } \\
\text { I: } 10,000 \\
\text { epinephrine }\end{array}$ & $\begin{array}{l}\text { Chart review } \\
\text { of pain } \\
\text { postinjection } \\
\text { (rating } \mathrm{I}-10 \text { ) }\end{array}$ & $\begin{array}{l}\text { No mean values } \\
\text { published. } 4 \text { I Patients } \\
\text { bypassed subsequent } \\
\text { topical/block with } \\
\text { repeat injection }\end{array}$ & $\begin{array}{l}\text { No adverse events, } \\
\text { observed decrease } \\
\text { in bruising per } \\
\text { authors }\end{array}$ \\
\hline $\begin{array}{l}\text { Monheit } \\
\text { et } \mathrm{al}^{4}\end{array}$ & $\begin{array}{l}\text { Prospective, randomized, } \\
\text { single-blind, controlled trial. } \\
\text { NLF split-face comparison }\end{array}$ & 45 Patients & $\begin{array}{l}\text { Captique vs } \\
\text { Prevelle SILK } \\
(0.3 \% \text { lidocaine })\end{array}$ & $\begin{array}{l}\text { Patient VAS } \\
\text { rated } 0-10 \mathrm{~cm}\end{array}$ & $\begin{array}{l}50 \% \text { Less pain } \\
(P<0.05)\end{array}$ & $\begin{array}{l}\text { No difference } \\
\text { between treatment } \\
\text { groups }\end{array}$ \\
\hline $\begin{array}{l}\text { Levy } \\
\text { et al }\end{array}$ & $\begin{array}{l}\text { Prospective, randomized, } \\
\text { double-blind, controlled trial. } \\
\text { NLF split-face comparison }\end{array}$ & 60 Subjects & $\begin{array}{l}\text { Juvéderm Ultra } 3 \\
\text { with and without } \\
0.3 \% \text { lidocaine }\end{array}$ & $\begin{array}{l}\text { Patient VAS } \\
\text { rated } 0-10 \mathrm{~cm} \text {, } \\
\text { physician } \\
\text { observation }\end{array}$ & $\begin{array}{l}\text { Mean subject score } \\
3.6 \text { with vs } 5.8 \\
\text { without lidocaine } \\
(P<0.00 \mathrm{I}) \\
\text { Physician observed } \\
81 \% \text { patients with vs } \\
36 \% \text { without in } \\
\text { pain }(P<0.00 \mathrm{I})\end{array}$ & $\begin{array}{l}\text { No significant } \\
\text { difference } \\
\text { between outcomes } \\
\text { of treatment groups }\end{array}$ \\
\hline $\begin{array}{l}\text { Levy } \\
\text { et al' }\end{array}$ & $\begin{array}{l}\text { Prospective, randomized, } \\
\text { single-blind, randomized } \\
\text { controlled trial. NLF } \\
\text { split-face comparison }\end{array}$ & I 26 Subjects & $\begin{array}{l}\text { Juvéderm Ultra } 3 \\
\text { (0.3\% lidocaine) vs } \\
\text { Restylane-Perlane }\end{array}$ & $\begin{array}{l}\text { Patient British } \\
\text { Pain Scale } \\
\text { (0-10 rating) }\end{array}$ & $\begin{array}{l}\text { Lower pain scores } \\
\text { with lidocaine }(P< \\
0.0001) .95 \% \text { patient } \\
\text { preferred Juvéderm } \\
\text { Ultra } 3\end{array}$ & $\begin{array}{l}\text { More reports with } \\
\text { Restylane-Perlane, } \\
\text { particularly more } \\
\text { reports of swelling } \\
\text { without lidocaine }\end{array}$ \\
\hline $\begin{array}{l}\text { Lupo } \\
\text { et } \text { al }^{17}\end{array}$ & $\begin{array}{l}\text { Prospective, randomized, } \\
\text { double-blind, controlled trial. } \\
\text { NLF split-face comparison }\end{array}$ & I 8 Subjects & $\begin{array}{l}\text { Large particle } \\
\text { hyaluronic acid } \\
\text { with and without } \\
2 \% \text { lidocaine }\end{array}$ & $\begin{array}{l}\text { Patient } \\
\text { questionnaire, } \\
\text { Canfield } \\
\text { photography, } \\
\text { blind physician } \\
\text { evaluations }\end{array}$ & $\begin{array}{l}\text { Significantly less } \\
\text { pain with lidocaine } \\
\text { per patients and } \\
\text { Physicians }\end{array}$ & $\begin{array}{l}\text { Trend toward less } \\
\text { bruising and redness } \\
\text { with lidocaine }\end{array}$ \\
\hline $\begin{array}{l}\text { Weinkle } \\
\text { et } \mathrm{al}^{8}\end{array}$ & $\begin{array}{l}\text { Prospective, randomized, } \\
\text { double-blind, controlled trial. } \\
\text { NLF split-face comparison }\end{array}$ & 72 Subjects & $\begin{array}{l}\text { Juvéderm with } \\
\text { and without } \\
\text { lidocaine }(0.3 \%)\end{array}$ & $\begin{array}{l}\text { Patient } \\
\text { II-point } \\
\text { pain scale }\end{array}$ & $\begin{array}{l}\text { Mean score of } 2.0 \\
\text { with vs } 5.3 \text { without } \\
(P<0.00 \text { I })\end{array}$ & $\begin{array}{l}\text { No significant } \\
\text { difference } \\
\text { between outcomes } \\
\text { of treatment groups }\end{array}$ \\
\hline Wahl' & Prospective case series & 3566 Subjects & $\begin{array}{l}\text { Juvéderm Ultra } \\
\text { with } 0.3 \% \\
\text { lidocaine }\end{array}$ & $\begin{array}{l}\text { Patient British } \\
\text { Pain Scale } \\
\text { (0-10 rating) }\end{array}$ & $\begin{array}{l}\text { Mean scores } \\
\text { of } 2.7,1.4,2.6 \text { during } \\
\text { injection, massage, } \\
\text { and } 5-10 \text { min } \\
\text { postinjection }\end{array}$ & $\begin{array}{l}\text { No reportable } \\
\text { adverse reactions }\end{array}$ \\
\hline
\end{tabular}

Abbreviation: VAS, visual analog scale.

comparison was completed on 45 subjects who rated their pain on a visual analog scale (VAS) at $0,15,30,45$, and $60 \mathrm{~min}$ postinjections (rating $0-10 \mathrm{~cm}$ ). A patient questionnaire and wrinkle severity assessment were also completed. Subjects reported more than 50\% less pain on the VAS with Prevelle SILK at all time points postinjection $(P<0.05)$ with the greatest difference at the time of injection. There were no significant differences between groups in cosmetic results or side effects. ${ }^{4}$

Levy et al conducted a prospective, randomized, doubleblind, controlled trial comparing Juvéderm Ultra 3 with and without preincorporated lidocaine. A split-face NLF injection comparison was completed on 60 subjects from three European centers, using topical anesthetic per 'routine' by each practitioner. Patients evaluated pain on a VAS postinjection (rating $0-10 \mathrm{~cm}$ ), and physicians evaluated severity of patient's pain. Patients rated pain significantly less with lidocaine on the VAS (3.6 vs 5.8; $P<0.001$ ). Physicians' assessment revealed $81 \%$ of injections with lidocaine produced no or mild injection pain, compared with $36.2 \%$ of HA gel alone $(P<0.001){ }^{3}$

Levy et al also conducted a prospective, randomized, single-blind controlled trial comparing Juvéderm Ultra 3 $(0.3 \%$ lidocaine) and Restylane-Perlane. A split-face NLF injection comparison was completed on 126 subjects recruited from three treatment centers. All injections were administered without any additional anesthesia. Pain was evaluated using the British Pain Scale (0-10 rating). Subjects 
reported significantly less pain at injection, with massage and postinjection with Juvéderm Ultra 3 compared to Restylane-Perlane $(P<0.0001)$. Postinjection smoothness was indistinguishable per physicians and subjects. Both groups experienced mild adverse reactions; more complaints were reported with Restylane, particularly postinjection swelling. When surveyed, 95\% of subjects preferred future injections with Juvéderm Ultra $3 .{ }^{1}$

Lupo et al conducted a prospective, randomized, doubleblind, controlled trial comparing large gel particle HA dermal fillers with and without $2 \%$ adjunct lidocaine. A split-face NLF comparison was completed on 18 subjects. Patient questionnaires revealed significantly less pain with lidocaine use and a trend toward less bruising and erythema, confirmed by both Canfield photography and blinded physician evaluation. All (100\%) patients and physicians agreed that there was no significant difference between cosmetic result and duration of effect. ${ }^{17}$

Weinkle et al conducted a prospective, randomized, double-blind controlled trial comparing Juvéderm Ultra and Juvéderm Ultra Plus ( $0.3 \%$ lidocaine). Split-face NLF injections were completed on 72 subjects from 4 different practices. Investigators could only provide additional topical anesthesia with ice and/or topical eutectic mixture of local anesthetics (EMLA). On an 11-point scale, the mean subject mean procedural pain score was 2.0 with lidocaine versus 5.3 without $(P<0.001){ }^{8}$

Wahl conducted a prospective case series of Juvéderm Ultra with lidocaine $(0.3 \%)$ on patients with previous experience with HA fillers without lidocaine. A total of 3566 patients were treated by 485 injectors in 16 different European countries. Investigators could use EMLA cream per routine. On a British Pain Scale (0-10 rating), patients mean pain levels were $2.7,1.4$, and 2.6 , respectively, during injection, massaging/sculpting, and 5-10 min postinjection. Patients rated Juvéderm Ultra as easy to inject (76.2\%) and easy to sculpt $(70.7 \%)$ and were satisfied with results (over $90 \%$ ). Over $95 \%$ of injectors rated the aesthetic effect of Juvéderm Ultra with lidocaine as 'excellent' or 'good'. ${ }^{18}$

\section{Adverse events: HA fillers with lidocaine}

This article focuses on the side effect of pain with HA filler treatment. Here, we review several of the other documented adverse reactions to be considered.

A retrospective review by $\mathrm{McCracken}$ et al of 236 patients treated with HA dermal fillers (Restylane) without lidocaine reports a low percentage of side effects. These included bruising (5\%), swelling (4\%), bumpiness (3\%), asymmetry $(3 \%)$, and erythema/discoloration ( $1 \%)$ that were primarily self-limiting within the first 1-2 weeks postinjection. ${ }^{6}$ The rate of complications do not appear significantly different among different Fitzpatrick Skin Types. ${ }^{19}$

More rare complications include superficial placement of filler and a resultant bluish or yellow discoloration (Tyndall effect dependent on product type), granulomatous or nodular reactions, and focal necrosis. ${ }^{20,21}$ Three cases of focal ischemia and necrosis were reported to the spontaneous drug adverse events reporting (SAER) systems of the United States in 2004, all of which were believed to be secondary to injection-related vascular complications. ${ }^{21}$

Several physicians report on adding lidocaine within the clinical setting to available manufactured product. Concerns of using this technique include compromising the quality, consistency, efficacy, volume, flow characteristics, and possibly the sterility of the product. Increased volume could distort the tissue, making it more difficult to predict postinjection outcomes. The majority of allergic reactions to fillers are attributed to preservatives and contaminants, while preincorporated products have preservative-free lidocaine with the same flow characteristics, consistency, volume, and concentration as those without. ${ }^{8}$

Although extremely rare, true lidocaine allergy cannot be disregarded. Most reactions to local anesthetics can be isolated to other product constituents, such as epinephrine preparations, or cross-sensitization to both the local anesthetic and these constituents. Rare reported cases of true lidocaine allergy primarily report type I immediate hypersensitivity reactions with associated contact dermatitis. There are fewer reports of type IV delayed reactions. ${ }^{22,23}$ Several cases of true allergy are attributed to sensitization from use of over-thecounter anesthetic products. ${ }^{23}$ This should be considered in the process of obtaining patient history and consent, as well as in the preparation of dermal fillers with local anesthetic.

There are several acute and delayed inflammatory and hypersensitivity reactions that are attributed to contamination of by-products from bacterial fermentation or preservatives instead of HA. ${ }^{1,13,20}$ In a European review of adverse reactions associated with dermal fillers, Andre et al reported that a small amount of proteins are found in HA dermal fillers. ${ }^{24}$ In 2000, a review of HA fillers injections from Q-Medicis Corporation revealed that in 12,344 injections in 4320 patients, 34 cases of hypersensitivity ( 16 immediate, 18 delayed) were reported for a global risk of $0.8 \%$. This risk was reduced to $0.6 \%$ in 2005 due to decreased protein load within injections. ${ }^{24}$ 
A retrospective case series by Van Dyke et al highlights the occurrence of severe, acute local reactions and nodular, sterile abscess formation to Elevess in three separate case reports. Each patient developed nodular, sterile abscesses within the site of injection, requiring oral antibiotics and steroids, and then markedly improved after aspiration and hyaluronidase injection. All aspirates were culture negative. The authors suggested a potential immunogenic protein contaminant in the HA component of the filler considering marked improvement of symptoms after aspiration and hyaluronidase treatment. ${ }^{13}$ This dermal filler is currently available in the United States under the name Hydrelle.

Several case reports of immediate and delayed nodule or bump formation at the site of injection exist for HA fillers. Narins et al reviewed six cases reported to the US SAER in 2004. All immediate cases developed within 2- to 7-week postinjection requiring medial therapy and for some, needle aspiration. ${ }^{21}$ Delayed reactions are also reported to occur over 12 -month postinjection. A review of voluntary reports generated and collected by the Spanish Society of Cosmetic Medicine and Surgery from 2004 to 2006 revealed 25 such cases involving HA fillers (15 patients: Juvederm, 2; Restylane, 12; and Hyalsystem, 1), HA with acrylic hydrogel fillers (9 patients: Dermalive, 9), and 1 patient who received a combined treatment (Resylane and Dermalive). Reactions occurred at an average of 13.7-month postinjection for HA fillers and 20.3 months for HA fillers with acrylic hydrogels. Of the 15 HA filler patients with adverse reactions, 2 were previously treated with a product with acrylic hydrogel. Ten of the 15 patients who received HA fillers obtained follow-up of which 4 experienced recurrent disease, 1 had residual disease, 3 were presumed cured, and 2 were lost to follow-up after their initial presentation. The authors reported medical therapy with oral nonsteroidals, antihistamines, low-dose oral and local steroids, and topical tacrolimus $(0.1 \%) .{ }^{14}$ The etiology of these nodules and bumps is debated throughout the literature to be either cell-mediated immune or foreignbody immune reactions. ${ }^{14,21}$ The multiple case reports of nodule and abscess formation available suggest patients should be informed of the possibility of this rare complication prior to treatment.

Nodules and bumps can also form due to infectious or even viral etiology. Dermal fillers may trigger recurrent herpetic lesions according to several studies. It is recommended that practitioners consider pretreatment with oral antiviral medications if there is a history of herpes or cold sores. Patients with active lesions should defer tissue augmentation until lesions are completely resolved..$^{21,25}$

\section{Discussion}

All studies within this review consistently show patients have significantly decreased pain with injections with adjunct lidocaine. Patients and investigators report this both during administration and postinjection. The majority of patients reported improved overall experience and preference for HA filler treatment with adjunct lidocaine for future treatments. There was no documented compromise to efficacy or duration of action with adjunct lidocaine compared to injections without. ${ }^{1-4,8,17}$

HA has a relatively low side effect profile since it is without species or chemical specificity. Treatments with adjunct lidocaine do not appear to significantly change this profile. Several studies suggest adjunct lidocaine decreases swelling, erythema, and even bruising. ${ }^{1,2,17}$ The use of lidocaine with epinephrine in one study could affect the interpretation of these observations. ${ }^{2}$

The potential for an adverse reaction to HA dermal fillers is a reality. Irrespective of skin type, most symptoms of bruising, swelling, bumpiness, asymmetry, erythema, and discoloration are uncommon and self-limited within the first couple of weeks postinjection. ${ }^{6}$ More rare complications include superficial placement, focal necrosis, herpetic recurrence, and nodular reactions. Nodular reactions may occur within weeks or may be delayed by over 12 months postinjection primarily due to cell-mediated immune or foreign body immune reactions. Allergic reactions to different constituents within the filler, contaminants, or rarely, true allergy to lidocaine must also be considered. ${ }^{13,14,19-23,25}$ Practitioners should be cognizant of these potential adverse effects in patient evaluation and consent for treatment.

\section{Conclusions}

It is believed that the ideal filler should have three key qualities: safety, effectiveness, and cost efficiency. Safety suggests a low risk of infection, extrusion, migration, or granulomatous formation. Effectiveness means it consistently creates natural filling of lines and/or augmentation of facial contours with reproducible results. Cost efficiency suggests the treatment has minimal downtime and an expense inverse to the duration. ${ }^{26}$ From our review, we suggest a fourth element be considered, aesthetic. The treatment should be geared to the needs and demands of a cosmetic patient, with minimized discomfort and recovery, which in turn can augment patient satisfaction with the result.

HA dermal fillers with adjunct lidocaine significantly decrease pain during injection and postinjection without other significant change to its side effect profile. Practitioners 
should be aware of rare complications due to additional constituents, contaminants, and lidocaine. Several studies even observed that the addition of lidocaine appeared to decrease erythema, bruising, and swelling, which may be due to the antihistamine properties of lidocaine. Although the significance of these observations remains unknown, this presents an interesting area of further study.

Considering the large market share and annual revenue of HA dermal fillers, there is ample benefit to improving the patient experience. We recommend making the option of HA filler treatment with lidocaine routinely available to patients.

\section{Disclosure}

The authors report no conflicts of interest in this work.

\section{References}

1. Levy PM, de Boulle K, Raspaldo H. A split-face comparison of a new hyaluronic acid facial filler containing pre-incorporated lidocaine versus a standard hyaluronic acid facial filler in the treatment of naso-labial folds. J Cosmet Laser Ther. 2009;11(3):169-173.

2. Beasley KL, Weiss MA, Weiss RA. Soft tissue augmentation using a two-way connector to supplement hyaluronic acid filler with $1 \%$ lidocaine hydrochloric acid with epinephrine 1:100,000: our experience and observations. Dermatol Surg. 2010;36(4):524-526.

3. Levy PM, de Boulle K, Raspaldo H. Comparison of injection comfort of a new category of cohesive hyaluronic acid filler with preincorporated lidocaine and a hyaluronic acid filler alone. Dermatol Surg. 2009;35 Suppl 1:332-336; discussion 337.

4. Monheit GD, Campbell RM, Neugent H, et al. Reduced pain with use of proprietary hyaluronic acid with lidocaine for correction of nasolabial folds: a patient-blinded, prospective, randomized controlled trial. Dermatol Surg. 2010;36(1):94-101.

5. Research B. Cosmetic surgery markets: products and services. Last updated 2008. Available from: http://www.reportlinker.com/p0132720/ Cosmetic-Surgery-Markets-Products-and-Services.html. Accessed October 8, 2010.

6. McCracken MS, Khan JA, Wulc AE, et al. Hyaluronic acid gel (Restylane) filler for facial rhytids: lessons learned from American Society of Ophthalmic Plastic and Reconstructive Surgery member treatment of 286 patients. Ophthal Plast Reconstr Surg. 2006;22(3):188-191.

7. Rohrich RJ, Herbig KS. Minimizing pain, maximizing comfort: a new technique for facial filler injections. Plast Reconstr Surg. 2009;124(4): 1328-1329.

8. Weinkle SH, Bank DE, Boyd CM, Gold MH, Thomas JA, Murphy DK. A multi-center, double-blind, randomized controlled study of the safety and effectiveness of Juvéderm injectable gel with and without lidocaine. J Cosmet Dermatol. 2009;8(3):205-210.
9. Brandt FS, Cazzaniga A. Hyaluronic acid gel fillers in the management of facial aging. Clin Interv Aging. 2008;3(1):153-159.

10. Custis T, Beynet D, Carranza D, Greco J, Lask GP, Kim J. Comparison of treatment of melomental fold rhytides with cross-linked hyaluronic acid combined with onabotulinumtoxina and cross-linked hyaluronic acid alone. Dermatol Surg. 2010;36 Suppl 3:1852-1858.

11. Carruthers J, Carruthers A. A prospective, randomized, parallel group study analyzing the effect of BTX-A (Botox) and nonanimal sourced hyaluronic acid (NASHA, Restylane) in combination compared with NASHA (Restylane) alone in severe glabellar rhytides in adult female subjects: treatment of severe glabellar rhytides with a hyaluronic acid derivative compared with the derivative and BTX-A. Dermatol Surg. 2003;29(8):802-809.

12. Baumann L. Dermal fillers. J Cosmet Dermatol. 2004;3(4):249-250.

13. Van Dyke S, Hays GP, Caglia AE, Caglia M. Severe acute local reactions to a hyaluronic acid-derived dermal filler. J Clin Aesthet Dermatol. 2010;3(5):32-35.

14. Alijotas-Reig J, Garcia-Gimenez V. Delayed immune-mediated adverse effects related to hyaluronic acid and acrylic hydrogel dermal fillers: clinical findings, long-term follow-up and review of the literature. J Eur Acad Dermatol Venereol. 2008;22(2):150-161.

15. Pinsky MA, Thomas JA, Murphy DK, Walker PS; Juvéderm vs Zyplast Nasolabial Fold Study Group. Juvéderm injectable gel: a multicenter, double-blind, randomized study of safety and effectiveness. Aesthet Surg J. 2008;28(1):17-23.

16. Librowski T, Pytka K, Szaleniec M. Antihistaminic activity of carane derivatives in isolated guinea pig ileum. Pharmacol Rep. 2009;61(6): 1211-1215.

17. Lupo MP, Swetman G, Waller W. The effect of lidocaine when mixed with large gel particle hyaluronic acid filler tolerability and longevity: a six-month trial. J Drugs Dermatol. 2010;9(9):1097-1100.

18. Wahl G. European evaluation of a new hyaluronic acid filler incorporating lidocaine. J Cosmet Dermatol. 2008;7(4):298-303.

19. Grimes PE, Thomas JA, Murphy DK. Safety and effectiveness of hyaluronic acid fillers in skin of color. J Cosmet Dermatol. 2009;8(3): $162-168$.

20. Bachmann F, Erdmann R, Hartmann V, Wiest L, Rzany B. The spectrum of adverse reactions after treatment with injectable fillers in the glabellar region: results from the Injectable Filler Safety Study. Dermatol Surg. 2009;35 Suppl 2:1629-1634.

21. Narins RS, Jewell M, Rubin M, Cohen JL, Strobos J. Clinical conference: management of rare events following dermal fillers - focal necrosis and angry red bumps. Dermatol Surg. 2006;32(3):426-434.

22. Kohase H, Umino M. Allergic reaction to epinephrine preparation in 2\% lidocaine: two case reports. Anesth Prog. 2004;51(4):134-137.

23. Mackley CL, Marks JG Jr, Anderson BE. Delayed-type hypersensitivity to lidocaine. Arch Dermatol. 2003;139(3):343-346.

24. Andre P, Lowe NJ, Parc A, Clerici TH, Zimmermann U. Adverse reactions to dermal fillers: a review of European experiences. J Cosmet Laser Ther. 2005;7(3-4):171-176.

25. Cohen JL. Understanding, avoiding, and managing dermal filler complications. Dermatol Surg. 2008;34 Suppl 1:S92-S99.

26. Cockerham K, Hsu VJ. Collagen-based dermal fillers: past, present, future. Facial Plast Surg. 2009;25(2):106-113.

Patient Preference and Adherence

\section{Publish your work in this journal}

Patient Preference and Adherence is an international, peer-reviewed, open access journal focusing on the growing importance of patient preference and adherence throughout the therapeutic continuum. Patient satisfaction, acceptability, quality of life, compliance, persistence and their role in developing new therapeutic modalities and compounds to

Dovepress

optimize clinical outcomes for existing disease states are major areas of interest. This journal has been accepted for indexing on PubMed Central. The manuscript management system is completely online and includes a very quick and fair peer-review system. Visit http://www.dovepress.com/ testimonials.php to read real quotes from published authors. 